\title{
Mining Induced Seismic Event on an Inactive Fault
}

\author{
Grzegorz LIZUREK, Łukasz RUDZIŃSKI \\ and Beata PLESIEWICZ
}

\author{
Institute of Geophysics, Polish Academy of Sciences, Warszawa, Poland \\ e-mail: lizurek@igf.edu.pl
}

\begin{abstract}
On 19 March 2013, a tremor shook the surface of Polkowice town where the Rudna Mine is located. This event, of $M L=4.2$, was the third most powerful seismic event recorded in the Legnica Głogów Copper District (LGCD). Inhabitants of the area reported that the felt tremor was bigger and lasted longer than any other ones felt in the last couple of years. Analysis of spectral parameters of the records from in-mine seismic system and surface LUMINEOS network along with broadband station KSP record were carried out. The location of the event was close to the Rudna Główna Fault zone; the nodal planes orientations determined with two different approaches were almost parallel to the strike of the fault. The mechanism solutions were also obtained as Full Moment Tensor from $P$-wave amplitude pulses of underground records and waveform inversion of surface network seismograms. The results from the seismic analysis along with macroseismic survey and observed effects from the destroyed part of the mining panel indicate that the mechanism of the event was complex rupture initiated as thrust faulting on an inactive tectonic normal fault zone. The results confirm that the fault zones are the areas of higher risk, even in case of carefully taken mining operations.
\end{abstract}

Key words: focal mechanism, full moment tensor, mining induced seismicity.

Ownership: Institute of Geophysics, Polish Academy of Sciences;

(C) 2015 Lizurek et al. This is an open access article distributed under the Creative Commons Attribution-NonCommercial-NoDerivs license,

http://creativecommons.org/licenses/by-nc-nd/3.0/. 


\section{INTRODUCTION}

Fault zones in underground mining operations are considered as potentially dangerous zones, where excavation works may be complicated and can cause various geomechanical issues that may lead to roof instability (e.g., Tajduś et al. 1996, Medhurst et al. 2008). Therefore, in regions of intense mining production all fault zones are treated with special care. In tectonically active zones, most of the seismic events are located along discontinuities in the rockmass, such as fault zones. In the case of Legnica Głogów Copper District (LGCD), Western Poland, the tectonic activity is not considered. There is only a small subsidence up to $1 \mathrm{~mm} /$ year (Zuchiewicz et al. 2007). The main fault zones in the vicinity of LGCD such as Sudetic Marginal Fault are considered not active as well as most discontinuities in Western Poland (Zuchiewicz et al. 2007), although two unexpected seismic events of magnitudes 2.8 and 3.8 occurred in 2007 and 2012, respectively, and were connected with movement along a small local normal fault near Jarocin (Lizurek et al. 2013). The Carpathian Mountains in the southern part of Poland are moderately active tectonically. This tectonic activity is accompanied by seismicity (e.g., Wiejacz and Dębski 2009, Guterch et al. 2005, Guterch and Lewandowska-Marciniak 2002). This seismically active area is about $300-400 \mathrm{~km}$ away from the LGCD; therefore, all the seismicity reported in the LGCD region is considered as a mining induced seismicity (Gibowicz and Kijko 1994). The anthropogenic seismic activity of LGCD is related to the copper ore underground exploitation in 3 mines: Rudna, Polkowice-Sieroszowice, and Lubin. Those mines produce annually several hundreds of seismic events with a local magnitude in the range of 0.4 to 4.5 (Lasocki 2005). The largest events in this area were $M l=4.5$ of 24 March 1977 (Gibowicz et al. 1979), and $M l=4.3$ of 20 June 1987 (Gibowicz et al. 1989) both located within the Lubin Mine. On 19 March 2013, a tremor shook the surface of Polkowice town where the Rudna Mine is located; inhabitants reported that it was one of the most powerful tremors they experienced in the last couple of years. The magnitude of this event, $m b=4.6$ according to EMSC (2013) and $M l=4.2$ according to IGF PAS, was the largest reported event since 1987 in this mining district. The seismic event was followed by a rockburst and several miners were trapped within the mining panel. Fortunately, there were no casualties, except of only two miners who were hurt and hospitalized. The event was reported to be located within G-3/4 mining panel of Rudna Mine, in the vicinity of Rudna Główna Fault. The aim of the study is to find if the mechanism of the event is connected with the existing fault zone nearby. To fulfil this goal we obtained two moment tensor solutions: the first one is obtained from the amplitudes of the first arrivals of waveforms recorded by in-mine seismic monitoring sys- 
tem, and the second one which supports the results by inversion of the waveforms from new surface local monitoring network Legnica-Głogów Underground Mining INduced Earthquake Observing System (LUMINEOS). Macroseismic questionnaires were also prepared and incorporated within local community for estimation of the tremors felt range, which was performed to find more information for an event depth determination (Lizurek et al. 2013).

\section{SITE AND DATA DESCRIPTION}

Rudna Mine is located in the Legnica-Głogów Copper District (LGCD), Southwestern Poland (Fig. 1). Mining in the Rudna Mine is carried out in three mining regions: Rudna Central, Rudna West, and Rudna North. The Rudna Mine operates 11 shafts ( 3 for extraction, 4 for ventilation, and 4 for personnel and materials) ranging from 950 to $1150 \mathrm{~m}$ in depth. The mine is operated by KGHM S.A. company (Kombinat Górniczo-Hutniczy Miedzi).

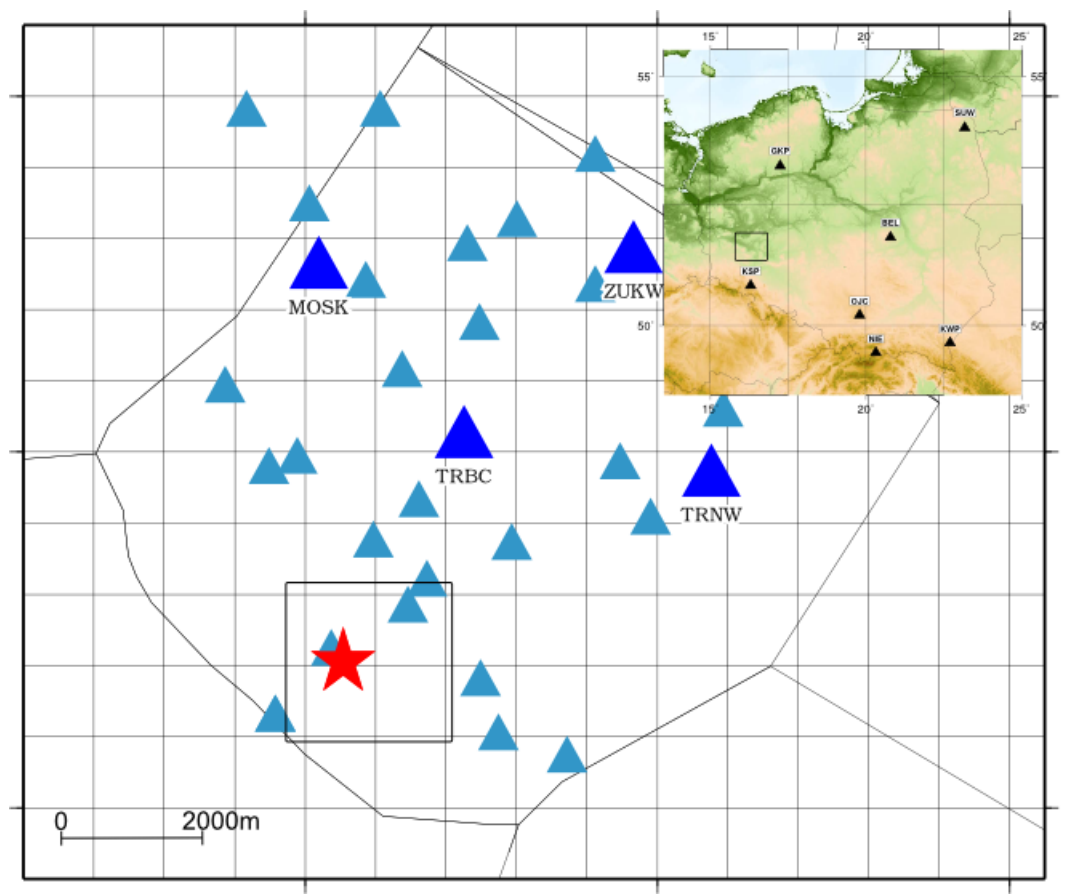

Fig. 1. Location of the 19 March 2013 seismic event and the seismic networks operating in the Polkowice area. Dark blue triangles denote LUMINEOS network stations and light blue triangles denote underground Rudna Mine seismic stations. The location of the considered mining panel is denoted with a rectangle. A topographic map of Poland with Polish Seismological Network broadband stations is in the upper right corner inset. The area of LGCD is denoted with black rectangle. 
The ore bearing strata includes Permian series of dolomite, shale and sandstone layers. Above them is the evaporate series composed of anhydrite and salt layers. The approximate depth of ore bearing layers is between 900 and $1100 \mathrm{~m}$. Ore is currently excavated at a depth of over $1150 \mathrm{~m}$, with an increase to a depth greater than $1200 \mathrm{~m}$ expected during the next several years. Below the copper ore strata lies the Rotliegend sandstone. Exploitation is performed in several mining panels. A pillar-chamber mining method is employed. In this system, the ore is separated into pillars and passages separated by structural pillars, which serve to support the roof. Blasting is the method used for extracting the copper ore due to its hardness (15$170 \mathrm{MPa}$ ) and the diversity of the ore body that comprises 3 types of rock: dolomite and sandstone, separated by a main layer of copper-bearing shale. Those parts of the ore, having a thickness of up to $7 \mathrm{~m}$, are worked out using the room-and-pillar method with an extra roof support; for ore having a thickness of over $7 \mathrm{~m}$ the room-and-pillar method is used with elimination of cavities by rock or hydraulic backfilling. The whole ore bearing strata are flat and slightly dipping towards NE (KGHM 2013). G-3/4 mining panel is located in southwestern part of Rudna Mine (Fig. 1). The Rudna Główna normal fault zone is located in north-eastern part of the panel; therefore, the panel lies in the hanging wall of this fault, which has NW-SE strike dipping to NE. Maximum fault throw values in this region are up to $4.5 \mathrm{~m}$; there are smaller faults located within the panel area with NW-SE and NE-SW strikes.

Seismicity induced in the Rudna Mine is quite high: annually there are several hundreds of events reported by the mine with magnitude range from 0.4 up to 4.2. Among them there are couple of high energy events $(M l>3.0)$ per month, for example in 2012 there were 2236 events of $M l$ above 0.9 , and 1626 events with $M l$ above 1.2, which was magnitude of completeness for the Rudna Mine seismic catalog in 2012. The maximum magnitude observed of Rudna Mine induced events in 2012 was 3.4. Seismicity in G-3/4 panel started in 2001 and was observed during all mining works carried in this area to April 2013. There were almost 2000 seismic events in this panel and 31 events with energy higher than $10^{7} \mathrm{~J}(M l>3)$. Activity varied from 0.12 to 0.56 events per day. The 19 March 2013 tremor has the highest energy released from the whole G-3/4 panel catalog.

Seismicity in the Rudna Mine is monitored continuously with local underground seismic network (Fig. 1), which is composed of 32 vertical seismometers at mining level; except of 5 sensors placed in elevator shafts, seismometers location depth varies from 300 down to $1000 \mathrm{~m}$ below surface. Epicenter location accuracy is about $50 \mathrm{~m}$ in terms of location uncertainty (Rudziński and Dębski 2011, Leśniak and Pszczoła 2008). The seismometers used in this network are vertical short-period Willmore MkII and MkIII sensors, with the frequency band from 1 to $100 \mathrm{~Hz}$. This system is designed for 
fast and precise location of events, but has some dynamic range limitations, which cause saturation of the $S$-wave part of the signal for high energy events at the nearest stations. Therefore, there are 4 stations doubled in the acquisition system and recording with lower gain to increase the ability of the network operator for more precise determination of the seismic energy released during seismic events. Lower gain stations have about 10 times lower gain coefficients: $1.5 \times 10^{-7} \mathrm{~m} / \mathrm{s}$ per count, while normal gain setting is $1.6 \times 10^{-8} \mathrm{~m} / \mathrm{s}$ per count. Examples of the saturated and unsaturated signals from the in-mine system are presented in Fig. 2.

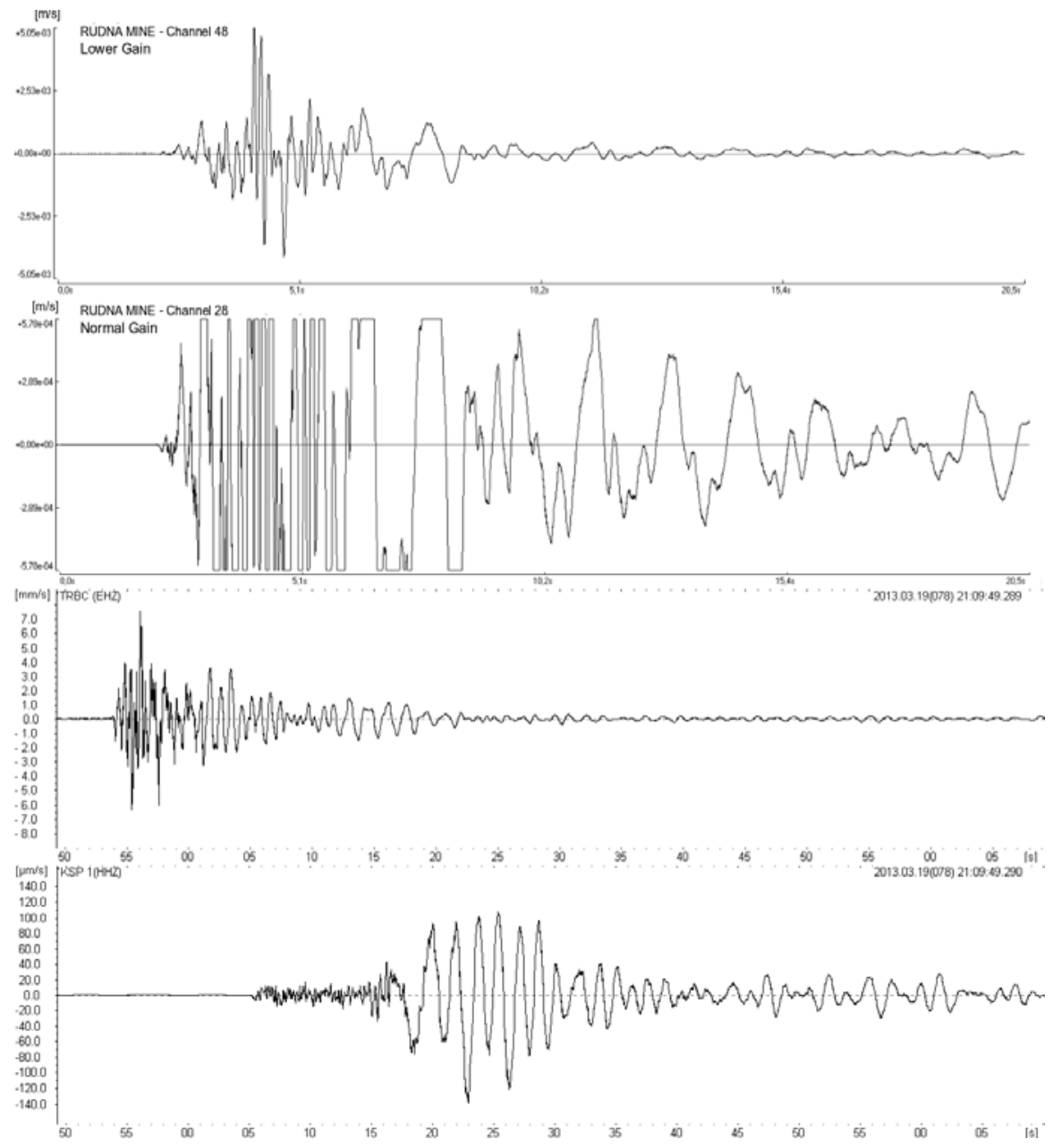

Fig. 2. Comparison of the signals recorded by Rudna Mine underground network (two upper traces, first one with lower gain, second one saturated), LUMINEOS network TRBC station, and broadband station KSP from PLSN. 
At the beginning of 2013 the local surface network of Institute of Geophysics, Polish Academy of Sciences (IGF PAS) with acronym LUMINEOS was installed under the agreement with KGHM S.A. and Rudna Mine officials. This network at the moment of the 19 March 2013 event (Fig. 1) was composed of 4 short-period one-second triaxial seismometers LE-3D/1s manufactured by Lenartz Electronics.

Initial locations of the event provided by the mine have been improved using Single Event Relocation Method (Rudziński and Dębski 2011) with the use of $P$-wave arrivals recorded on in-mine seismic system. The event was located in north-eastern part of mining panel in the vicinity of Rudna Główna Fault at the excavation level (Figs. 1 and 3).

Spectral analysis was applied to estimate source parameters such as seismic moment, seismic energy, radius, and slip (Table 1). Seismic moment

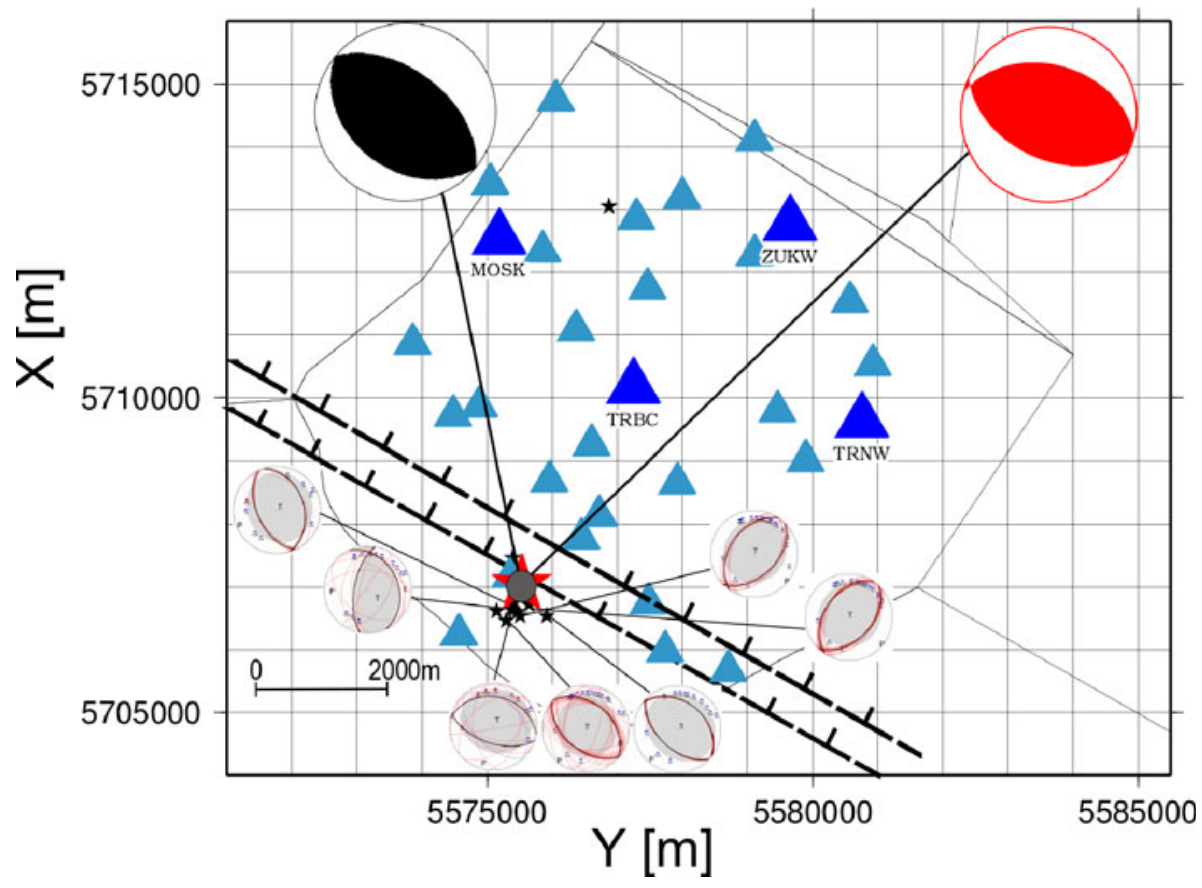

Fig. 3. Focal mechanism solutions presented as beach balls on the background of the Rudna Mine contour with underground seismic network (small light blue triangles) and LUMINEOS network (bigger dark blue triangles). On the left (black color) $P$-wave amplitude inversion fault plane solution is shown, and on the right (red color) waveform inversion fault plane solution is shown. The big star denotes epicentral location of the main event, the grey circle denotes epicenter location uncertainty, small stars present the aftershock locations with beach balls for the strongest of them, and the thick dashed line denotes Rudna Główna Fault zone margins. 
Table 1

Source parameters of the 19 March 2013 seismic event calculated from mine network, LUMINEOS network, and KSP broadband station records

\begin{tabular}{|c|c|c|c|c|c|c|c|c|c|c|}
\hline Station & $\begin{array}{c}F_{c} \\
{[\mathrm{~Hz}]}\end{array}$ & $\begin{array}{c}\text { energy } \\
{[\mathrm{J}]}\end{array}$ & $\begin{array}{c}S \text {-wave } \\
\text { energy } \\
{[\mathrm{J}]}\end{array}$ & $\begin{array}{c}\text { Seismic } \\
\text { energy } \\
{[\mathrm{J}]}\end{array}$ & $E_{s} / E_{p}$ & $\begin{array}{c}M_{0} \\
{[\mathrm{Nm}]}\end{array}$ & $M l$ & $M_{w}$ & $\begin{array}{c}\text { Radius } \\
{[\mathrm{m}]}\end{array}$ & $\begin{array}{l}\text { Slip } \\
{[\mathrm{m}]}\end{array}$ \\
\hline MOS & 3 & & $4.60 \times 10^{9}$ & $4.84 \times 10^{9}$ & 19.2 & $2.80 \succ$ & 4.3 & 3.6 & 175 & 0.11 \\
\hline TRBC & 3.2 & $7 \times 10^{7}$ & $84 \times 10^{9}$ & $92 \times 10^{9}$ & 23.9 & $1.82 \times 10^{14}$ & 4.1 & 3.0 & 198 & 06 \\
\hline TARN & 5.1 & $2 \times 10^{7}$ & $4.80 \times 10^{9}$ & $72 \times 10^{9}$ & .2 & & 4.4 & 3.4 & 125 & 09 \\
\hline ZUKW & 4.5 & & $32 \times 10^{9}$ & $.90 \times 10^{9}$ & 24.3 & $1.58 \times 10^{14}$ & 4.1 & 3.4 & 13 & 0.11 \\
\hline $\begin{array}{c}\text { Rudna } \\
\text { Mine } \\
\text { network }\end{array}$ & 2.7 & $\times 10^{8}$ & $1.72 \times 10^{9}$ & $1.85 \times 10^{9}$ & 13.2 & 5.58 & 4.1 & 3.8 & 223 & 0.13 \\
\hline KSP & 3 & $7.2 \times 10^{\circ}$ & $9.62 \times 10^{0}$ & $1.68 \times 10^{9}$ & 1.34 & $8.34 \times 10^{14}$ & 4.1 & 3.9 & & .30 \\
\hline Det & $\begin{array}{l}3.7 \\
\pm \\
0.9\end{array}$ & $\begin{array}{l}2.2 \times 10^{8} \\
2.5 \times 10^{8}\end{array}$ & $\begin{array}{c}2.62 \times 10^{9} \\
\pm \pm \\
1.6 \times 10^{9}\end{array}$ & $\begin{array}{c}2.84 \times 10^{y} \\
\pm \stackrel{ \pm}{ } 1.70^{9}\end{array}$ & $\begin{array}{c}11.9 \\
\pm \\
9.7\end{array}$ & $\begin{array}{c}3.56 \times 10^{14} \\
\pm \\
\pm .8 \times 10^{14}\end{array}$ & $\begin{array}{c}4.2 \\
\pm \\
0.2\end{array}$ & $\begin{array}{l}3.7 \\
\pm \\
0.2\end{array}$ & $\begin{array}{c}172 \\
\pm \\
38\end{array}$ & $\begin{array}{c}0.13 \\
\pm \\
0.09\end{array}$ \\
\hline
\end{tabular}

was calculated upon Boore and Boatwright (1984) assumption of lowfrequency level of the far-field displacement, seismic energy was calculated with the use of the Boatwright and Fletcher (1984) relation of radiated energy of $P$ and $S$ waves and the energy flux contained in the $P$ - and $S$-wave trains.

Source radius was calculated upon Brune $(1970,1971)$ formalism with the use of Madariaga (1976) circular fault model, which was also used for the slip estimation from Aki and Richards (1980) seismic moment definition. Moment magnitude was estimated from seismic moment (Hanks and Kanamori 1979), while local magnitude was estimated from empirical relation between energy estimates and local magnitude for LGCD; all the details of the estimation methods of the above-mentioned parameters were described by Gibowicz and Kijko (1994) and Niewiadomski (1997). The analysis was performed using unsaturated records of the seismic system of Rudna Mine, the records from LUMINEOS network and KSP broadband station of PLSN network, which is located about $80 \mathrm{~km}$ south from the epicentre. Signal examples from the above-mentioned networks are presented in Fig. 2.

The relevant parts of seismograms of $P$ and $S$ waves were selected manually, and then transformed by Fast Fourier Transformation (FFT). The resulting amplitude spectra were corrected for attenuation effects with $Q=400$ and 200, respectively, for $P$ and $S$ waves. For further calculations we set velocities of $P$ and $S$ waves in source at $V p=5900 \mathrm{~m} / \mathrm{s}$ and $V s=3400 \mathrm{~m} / \mathrm{s}$. 
The free surface correction for surface network and broadband stations were used, while in case of in-mine system the free surface correction can be neglected. Shear modulus was set at $2.7 \times 10^{10} \mathrm{Nm}^{-2}$; the account for $P$ - and $S$-wave radiations were set for 0.52 and 0.63 , respectively (Lizurek and Wiejacz 2011, Kwiatek 2013, Gibowicz and Kijko 1994). Far-field displacement spectra were approximated on logarithmic scale. The two asymptotes were calculated using of integrals of squared displacement and velocities of ground motion. This has allowed us to estimate the spectral plateau, corner frequency and energy flux in observation point for every spectrum of $P$ and $S$ waves.

Further energy of $P$ and $S$ waves was calculated from an energy flux in far field displacement. The average value of the seismic energy released during the event is $2.84 \times 10^{9} \mathrm{~J}$, average seismic moment $3.56 \times 10^{14} \mathrm{Nm}$, local magnitude 4.2, moment magnitude 3.7 , source radius $172 \mathrm{~m}$, and slip $13.3 \mathrm{~cm}$. These values are relatively high compared with the mining induced events in LGCD, where energy release is rarely above $10^{8} \mathrm{~J}$. In the past, such high energy release was noted for the two biggest events from LGCD: in 1977 with energy $2.5 \times 10^{10} \mathrm{~J}, M l=4.5$ (Gibowicz et al. 1979) and in 1987 event with $M l=4.3$ and energy $5.0 \times 10^{9} \mathrm{~J}$ (Gibowicz et al. 1989). $S$-wave to $P$-wave energy ratio is quite high - almost 12 in average, which is characteristic for tectonic earthquakes with shearing as a main rupture component, rather than for mining induced events, where non-shearing components may play a role in rupture process, especially in the case of LGCD mines (Gibowicz and Kijko 1994, Lizurek and Wiejacz 2011). Source parameters are comparable with the parameters obtained using the same methodology for tectonic seismic event near Jarocin from 6 January 2012 (Lizurek et al. 2013), but the mining induced event from 19 March 2013, was shallower, had higher energy release, larger slip value and higher magnitude, which made it more intensely felt on smaller area. The large event was followed by 10 aftershocks within the area of the G-3/4 mining panel during next 16 hours with the highest energy released, $7.1 \times 10^{4} \mathrm{~J}$. During the next month, only 4 events were reported for this mining panel, none of them with energy higher than $1 \times 10^{4} \mathrm{~J}$. The aftershock distribution does not follow the fault strike, but is dispersed over the vicinity of the studied event, mostly within the G-3/4 panel (Fig. 3).

\section{FOCAL MECHANISM}

Focal mechanism was calculated using two different approaches: the first one using the moment tensor inversion in the time domain from amplitudes of $P$-wave onset recorded by underground seismic network in Rudna Mine (Wiejacz 1992, Awad and Kwiatek 2005), the other using waveform inver- 
sion (Cesca et al. 2010) of the signals recorded with LUMINEOS network (Figs. 1 and 3).

\section{1 $P$-wave amplitude inversion}

Calculations of the moment tensor from the mine underground network records were performed using FOCI software 3.0 (Kwiatek 2013). The inversion of the $P$-wave amplitude was performed in time domain. The registered first onsets may be of different types: direct $P$ waves and refracted from the overlying anhydrite layer or the thick strata of sandstone underlying the ore deposit. This is caused by the geological situation. The layers are almost flat, the dip of the layers being about 4 degrees NE. The ore bearing strata are a dolomite layer of $60-90 \mathrm{~m}$ thickness. Above the ore bearing strata, there exists the evaporate series mainly composed of the anhydrite of $160 \mathrm{~m}$ thickness, and below the ore bearing strata there is a sandstone layer of about $300 \mathrm{~m}$ thickness.

The observation of seismic recordings from the in-mine system led to the conclusion that the direct $P$ wave is observed when the source-receiver distance is smaller than $1 \mathrm{~km}$, because the direct wave gradually disappears and only the refracted waves are observed at longer distance. The velocities determined for the waves were: $5 \mathrm{~km} / \mathrm{s}$ for the direct wave, $5.9 \mathrm{~km} / \mathrm{s}$ for the refracted wave from the overlying anhydrite layer, and $5.6 \mathrm{~km} / \mathrm{s}$ for the refracted wave from the underlying sandstone layer (Wiejacz 1992). In the present study all types of waves were used with 22 onsets on 22 stations; these were mostly the waves refracted from the overlying anhydrite layer, 2 onsets of wave refracted from the underlying sandstone strata, and only one direct wave onset was recorded at the station nearest to the source.

The input parameters are the amplitude and polarity information on the first $P$-wave displacement pulses. According to Fitch et al. (1980), the recorded displacement for the vertical component of the $P$-wave phase is:

$$
U_{z}^{P}(x, t)=\frac{1}{4 \pi \rho \alpha^{3} r}\left[\bar{\gamma} M \dot{s}\left(t-\frac{r}{\alpha}\right) \bar{\gamma}\right] l_{z},
$$

where $\rho$ is the average density, $r$ is the source-receiver distance, $\alpha$ is the average velocity of $P$ wave, $M$ is the seismic moment, $l_{z}$ is the cosine of the angle of the incidence, and $\bar{\gamma}$ is the take-off angle. The Source Time Function (STF) was based on the Haskell's source model (Haskell 1953):

$$
\dot{s}=\begin{gathered}
1 / T, 0<t<T \\
0, \quad \text { elswhere }
\end{gathered},
$$

where $T$ is the rupture time. 
Moment tensor is obtained by solution of a set of $N$ equations of type 1 . Due to the six independent elements of the moment tensor there must be at least six such equations, but the more, the better. When the condition of the zero trace is imposed on solution, the deviatoric moment tensor may be determined, which excludes the type of mechanism with volumetric change in the source. When the condition of zero trace and zero denominator are set, the solution is limited to the double couple source. The deviatoric, pure shear

Table 2

Source parameters (moment tensor and nodal planes) of the 19 March 2013, seismic event calculated from in-mine network, LUMINEOS network

\begin{tabular}{|c|c|c|c|c|}
\hline \multicolumn{3}{|c|}{ Moment tensor solutions } & $\begin{array}{l}\text { Nodal plane } \\
1 \text { orientation }\end{array}$ & $\begin{array}{l}\text { Nodal plane } \\
2 \text { orientation }\end{array}$ \\
\hline $\begin{array}{l}\text { Method } \\
\text { of inversion }\end{array}$ & $\begin{array}{c}\text { Tensor } \\
\text { components }\end{array}$ & {$[\mathrm{Nm}]$} & Strike/Dip/Rake & Strike/Dip/Rake \\
\hline Solution A & $\begin{array}{l}M_{11} \\
M_{22} \\
M_{33} \\
M_{12} \\
M_{13} \\
M_{23}\end{array}$ & $\begin{aligned}-1.26 & \times 10^{14} \\
-7.10 & \times 10^{13} \\
4.46 & \times 10^{14} \\
-6.76 & \times 10^{13} \\
4.49 & \times 10^{12} \\
-7.10 & \times 10^{13}\end{aligned}$ & $309 / 47 / 96$ & $120 / 43 / 83$ \\
\hline Solution B & $\begin{array}{l}M_{11} \\
M_{22} \\
M_{33} \\
M_{12} \\
M_{13} \\
M_{23}\end{array}$ & $\begin{aligned}-6.11 & \times 10^{14} \\
-3.99 & \times 10^{14} \\
4.51 & \times 10^{14} \\
-7.55 & \times 10^{13} \\
3.47 & \times 10^{13} \\
6.89 & \times 10^{13}\end{aligned}$ & $115 / 48 / 97$ & $285 / 42 / 83$ \\
\hline \multicolumn{5}{|c|}{ Decomposition components } \\
\hline Solution A & \multicolumn{2}{|c|}{$\begin{array}{l}\text { DC } \\
\text { CLVD } \\
\text { ISO }\end{array}$} & \multicolumn{2}{|c|}{$\begin{array}{l}42 \% \\
33 \% \\
25 \%\end{array}$} \\
\hline Solution B & & $\mathrm{D}$ & $\begin{array}{r}41 \\
9 \\
-50\end{array}$ & $\begin{array}{l}\% \\
\% \\
\%\end{array}$ \\
\hline \multicolumn{5}{|c|}{ Uncertainties of the methods } \\
\hline \multicolumn{5}{|c|}{ Nodal plane orientation uncertainty (Strike/Dip/Rake) } \\
\hline $\begin{array}{l}\text { Solution A } \\
\text { Solution B }\end{array}$ & & $\begin{array}{r} \pm 1 \\
\pm 24\end{array}$ & $\begin{array}{l}9 / 5 \\
1 / 10\end{array}$ & \\
\hline
\end{tabular}



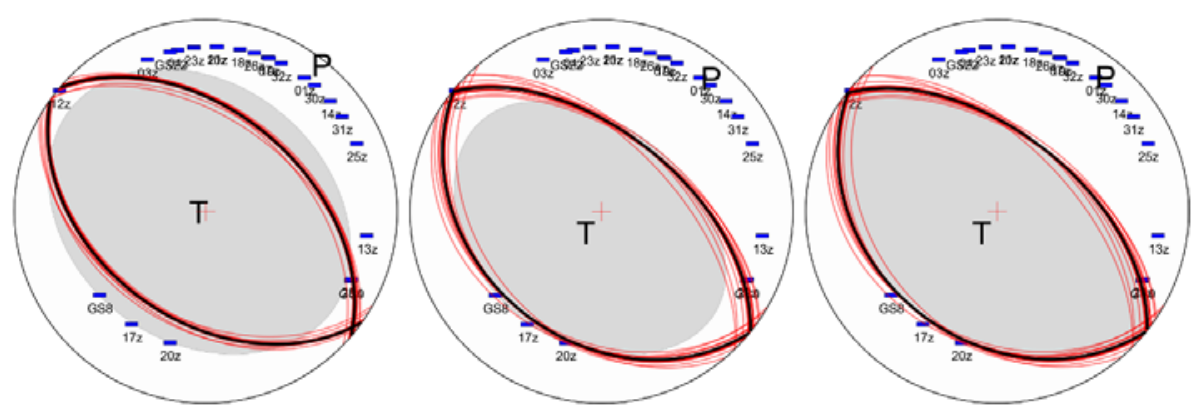

Fig. 4. Mechanism solutions with $P$-wave amplitude inversion (solution A) - from the left: Full Moment Tensor, Trace Null, and Double Couple solution. The numbers and signs denote the station location and polarization on focal sphere. All solutions are presented as a Lambert azimuthal equal-area projection on lower hemisphere Schmidt net. The red lines denote the nodal plane orientation for different station configurations of Jacknife test, and the black lines denote the nodal planes from the obtained solution with all stations used.

and full moment tensors were calculated using the L2 norm as a measure of the misfit (Wiejacz 1992, Awad and Kwiatek 2005). The sensor distance from the hypocenter was mainly above 1500 to $8000 \mathrm{~m}$ in case of in-mine system, with one exception of channel 12, which was about $200 \mathrm{~m}$ from the source. It is within source dimension radius, but it was the only channel with direct wave recorded. The Jacknife test of station influence on the result has shown (Fig. 3, Table 2) that it has no big influence on tensor components and nodal plane orientation, but the use of this channel allows to decrease the moment tensor uncertainty; therefore, it was included into the moment tensor inversion procedure. Moreover, the strike/dip/rake uncertainty was relatively small - not higher than 12 degrees. The result of the $P$-wave amplitude inversion approach will be named further as solution A. The full moment parameters along with decomposition for double-couple (DC), compensated linear vector dipole (CLVD) and isotropic (ISO) components are presented in Table 2 and Figs. 3 and 4. The maximum estimation error of the moment components calculated with FOCI (Awad and Kwiatek 2005) software was $1.08 \times 10^{13} \mathrm{Nm}$.

\subsection{Waveform inversion}

The moment tensor solution using LUMINEOS seismograms inversion was carried out with "kiwi tools" package (Heimann 2011), http://kinherd.org. Because the network consists of 4 three-component short period seismometers, it gave an opportunity to work with 12 traces in frequency range 1-50 Hz. The methodology adopted eikonal source model and multistep in- 
version strategy, as described by Cesca et al. (2010). It allowed to work with both amplitude spectra and seismograms (time traces) in time domain at different frequency ranges. The eikonal model can be described by 13 parameters which can be grouped into two groups; the first 8 parameters describe a point source while the last 5 are connected with finite rupture (Cesca et al. 2010). Parameters needed to describe the point source are: strike, dip, rake, scalar moment and latitude, longitude, depth, and origin time. These groups of parameters explain radiation pattern and locate the event in space and time. The remaining 5 are related to the finite rupture and can be obtained with knowledge of point source. The rupture propagates with relative rupture velocity $v_{r}$ within the rupture surface, with radius $R$ from nucleation point characterized by parameters nucleation coordinates $n_{x}$ and $n_{y}$. The last parameter is the rise time which defines the time required for the slip occurence at each point. The $v_{r}$ is defined as percentage of the shear velocity (Cesca et al. 2010). Since the LUMINEOS network is very sparse we decided, in this paper, to study only point source inversion. It means the result of the analysis was a focal mechanism described by strike, dip, rake for both nodal planes and scalar moment, centroid latitude, longitude, depth, and origin time. Enough information to obtain point source mechanism can be found in seismograms below the corner frequency (Gibowicz and Kijko 1994). The analysis was performed using the 1D (Fig. 5) very local velocity model for Rudna Mine (Dec et al. 2011).

The inversion procedure started with hypocentral location given by the relocated hypocentre with underground in-mine network (Figs. 1 and 3) and average scalar moment obtained by spectral analysis (Table 1). To avoid non-uniqueness caused by nonlinearity of the inversion problem, the inversion was run several times with different starting configuration. In this point, the varied starting parameters were source depth (in a range between 0.5 and $1.5 \mathrm{~km}$ with a $0.1 \mathrm{~km}$ step) Because the event was located outside the LUMINEOS network (Figs. 1 and 3), in the first step the fitting of amplitude spectra was preferred than seismogram fitting in the time domain. Such approach has some advantages and could give more reliable results in this case (Cesca et al. 2006).

All 12 displacement traces were used during the inversion. To stabilize the solution we decided to focus on $P$-waves onset. The chosen bandpass was $2.0-3.0 \mathrm{~Hz}$, which covered frequency range below the corner frequency of the recorded seismic waves. The recorded corner frequencies in LUMINEOS network were from 3.7 to $5.1 \mathrm{~Hz}$ (Table 1). The first 5 seconds of the seismograms were used in analysis. We decided to use this time interval to be sure that a long enough $P$ train was recorded even on the farthest station ZUKW. It was especially important in case of stability of spectral inversion step. The solutions were obtained with L2 norm. After the spectra 


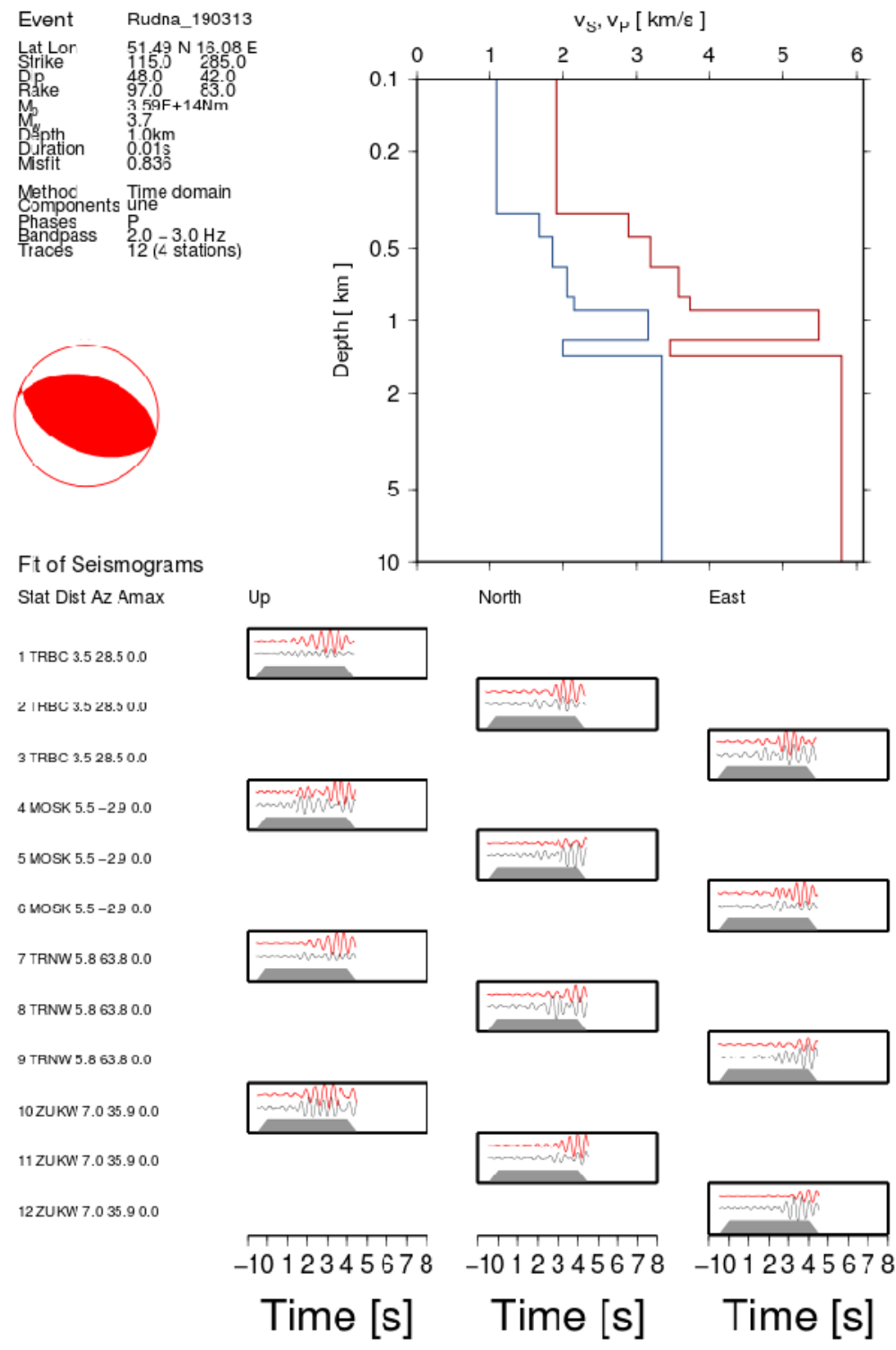

Fig. 5. Details of the inversion of the waveform results with velocity model based on Dec et al. (2011) (top-right panel). Inversion results contain point source parameters estimation and focal mechanism. Fit of $P$-waves seismograms for the used stations include observed (red) and synthetics displacements (blue). The gray shaded area is the applied time taper. The point source parameters are: strike: 115,285 ; dip: 48, 42; rake: 97, 83; moment magnitude: 3.7 , seismic moment: $3.59 \times 10^{14} \mathrm{Nm}$. The inversion used the $P$-wave trains and three components; u: vertical, n: N-S, e: E-N recorded on 12 traces on 4 stations. The frequency used: 2-3 Hz. 

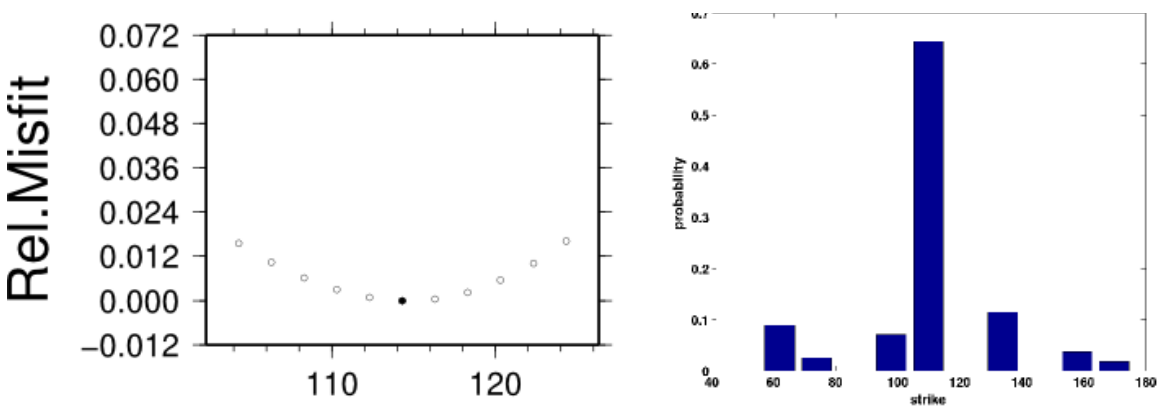

\section{Strike}
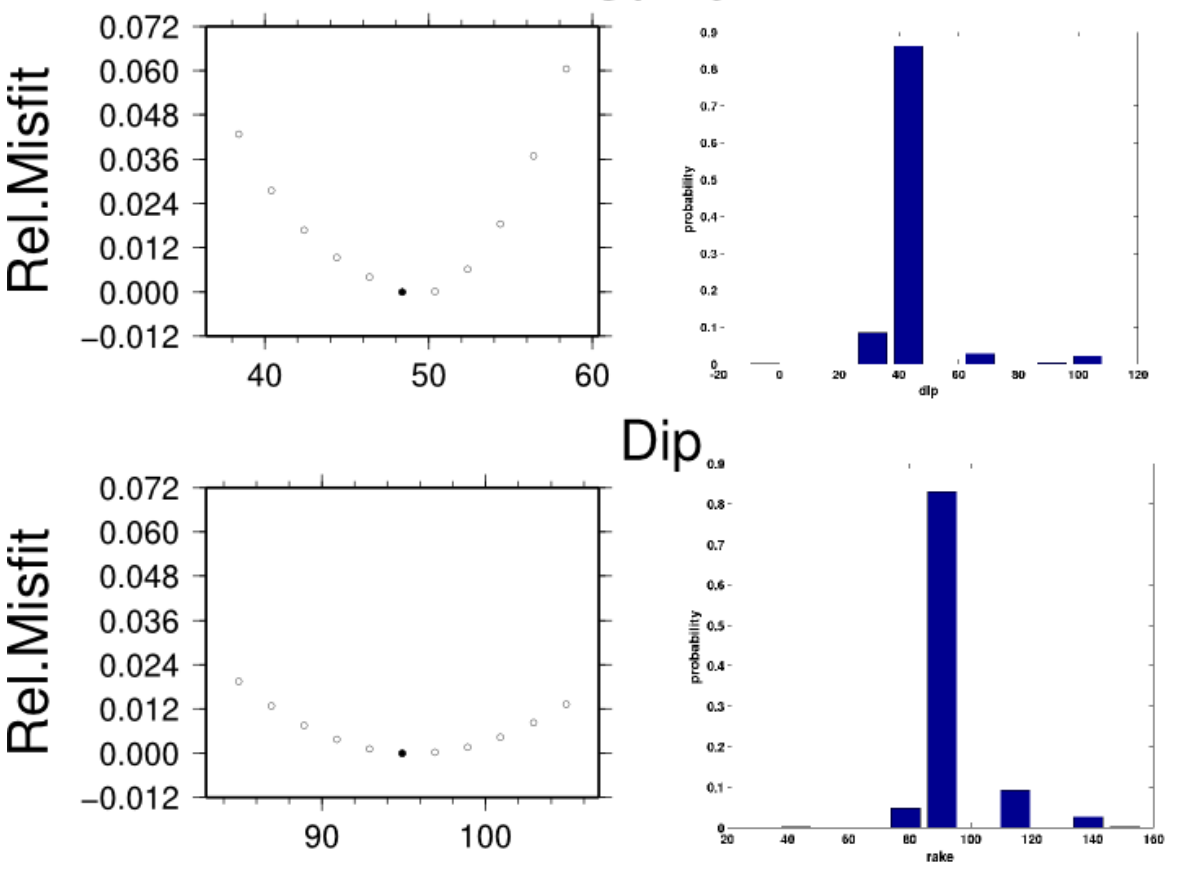

\section{Rake}

Fig. 6. Optimal solution for strike, dip, and rake (black circles) for one of the nodal planes obtained with spectral inversion step (left panel) and the result of the bootstrap test (right panel). The latter provide probability of the solution B. The histograms are shown for one of the nodal planes.

inversion optimization (Fig. 6) step, the fault parameters: strike, dip, rake for 2 possible fault configurations, scalar moment, and centroid depth were estimated. Since we used just spectra fitting, it was no information about polarities of seismograms. Without this, it is impossible to discriminate compression and dilatation quadrant. 
The main task for the second step was to fit the seismograms in time domain and, in practice, to include polarities into the analysis. The same frequency and time windowing like in the previous step were used for fitting seismograms. Synthetic seismograms were calculated for 2 possible fault configurations obtained with the first step and then optimization in L2 norm was used. The results of point source inversion are gathered in Table 2 and the best DC solution is presented in Fig. 5.

The solution B had a relatively high misfit measured in L2 norm as the difference between the amplitude spectra of the observed and synthetic seismograms. It is probably due to the azimuthal coverage and much more complicated velocity model with mostly unknown velocity for laterally variable subsurface sedimentary layer. Both of those issues can influence the obtained results. To be more sure that the solution is stable we provide a bootstrap test which repeatedly solves the inverse problem using a different subset of LUMINEOS seismic stations (Heimann 2011). We used 256 bootstrap samples to provide the probability of the solution B. Results of the test for one of the nodal planes are presented in Fig. 6 and the uncertainty of strike, dip and slip results are included in Table 2 . Let note that the stability is very high, but error estimates in the case of strike and rake were two times bigger than in solution A; nevertheless, the studied event was the first high-energy event recorded with LUMINEOS network.

\subsection{Interpretation of the results}

The focal mechanism of the studied event was a thrust fault of NW-SE orientation similar to the strike of Rudna Główna Fault. Both types of solutions are similar in terms of nodal plane orientations. The nodal plane strikes differ within 24 degrees at most, while dip differs only by 5 degrees, and rake differs up to 14 degrees, which is within the range of error estimates for solution B and slightly higher than the uncertainty of solution A (Table 2). Solution details are listed in Table 2. There was crucial difference in the azimuthal coverage of the stations used in both methods of mechanism estimations (Fig. 3). The azimuthal coverage was very good between NE and $\mathrm{SW}$ in the case of solution A, with only two stations on the opposite azimuth angles, while LUMINEOS stations cover about 60 degree angle from $\mathrm{N}$ to ESE. In the case of $P$-wave amplitude inversion method there was performed Jacknife test of the solution sensibility for the station distribution (Kwiatek 2013). The obtained result shows very small sensitivity for changes in station distribution performed by excluding single station from the station set and then repeating such action for all the stations (Fig. 4).

Full Moment Tensor decompositions show a similar double-couple (DC) component: $42 \%$ in solution A and $41 \%$ in solution B. In the latter one, the 
dominance of implosive component is observed (about 50\%), while solution A shows more complex decomposition with the highest value of DC component, but smaller than the sum of non-DC components (CLVD - 33\% and ISO $-25 \%)$. The $E s / E p$ ratio obtained with spectral analysis was about 12 , which may suggest the shearing mechanism. Lizurek and Wiejacz (2011) have shown that in case of Rudna Mine events the high $E s / E p$ ratio does not always indicate pure shearing mechanism, which is also the case of the studied event.

Relatively high non-DC components in the solution of focal mechanism in the case of mining induced events in comparison with tectonic earthquakes is not exceptional (e.g., Gibowicz and Kijko 1994, and literature therein). Mechanisms with implosive or explosive component were reported for LGCD mines (Wiejacz 1992). Recently the non-DC component of focal mechanism solution was also considered as an indicator of the induced seismicity (Cesca et al. 2013). On the other hand, in tectonic earthquakes nonDC components of mechanism solutions are considered a result of anisotropy of the rocks. Even in case of pure shear faulting, the non-DC values derived from full moment tensor solution can reach up to $30 \%$ (Vavryčuk 2005, Davi and Vavryčuk 2012). The solution A indicates that the mechanism was complex: a mix of shearing with one-axial tension and explosive component in total decomposition of full moment tensor, while in solution B the mechanism was rather closing of the excavation chamber with an upward movement of the floor, which is a hanging wall of Rudna Główna Fault. Those significant discrepancies of mechanism solutions needed further explanation, but due to essential differences between the methods used for the inversions and obtained quality measures of the results it is impossible to directly compare the obtained results in terms of misfit and error estimates. To solve these issues we provided the forward modelling of waveforms for both of those solutions and compared the synthetic waveforms obtained for 4 inmine stations with lower gain. Signals of the studied event recorded on those stations were characterised by not saturated beginning of the signal $(P$-wave train) and additionally those signals were not used for both of the obtained solutions.

Synthetic signals were obtained within frequency range of $2-3 \mathrm{~Hz}$, which corresponds with frequency range used for inversion of waveforms in the solution $\mathrm{B}$ and it is a range below the average corner frequency of the observed signals. However, it is worth to note that the first $P$-wave pulses used for solution A were not filtered and characterised by the $4-17 \mathrm{~Hz}$ range. A comparison was made with the use of signal correlation coefficient of the synthetic signal with the recorded one. The higher correlation coefficient the better the synthetic signal fits the recorded one. Results of the modelling are shown in Fig. 7. 

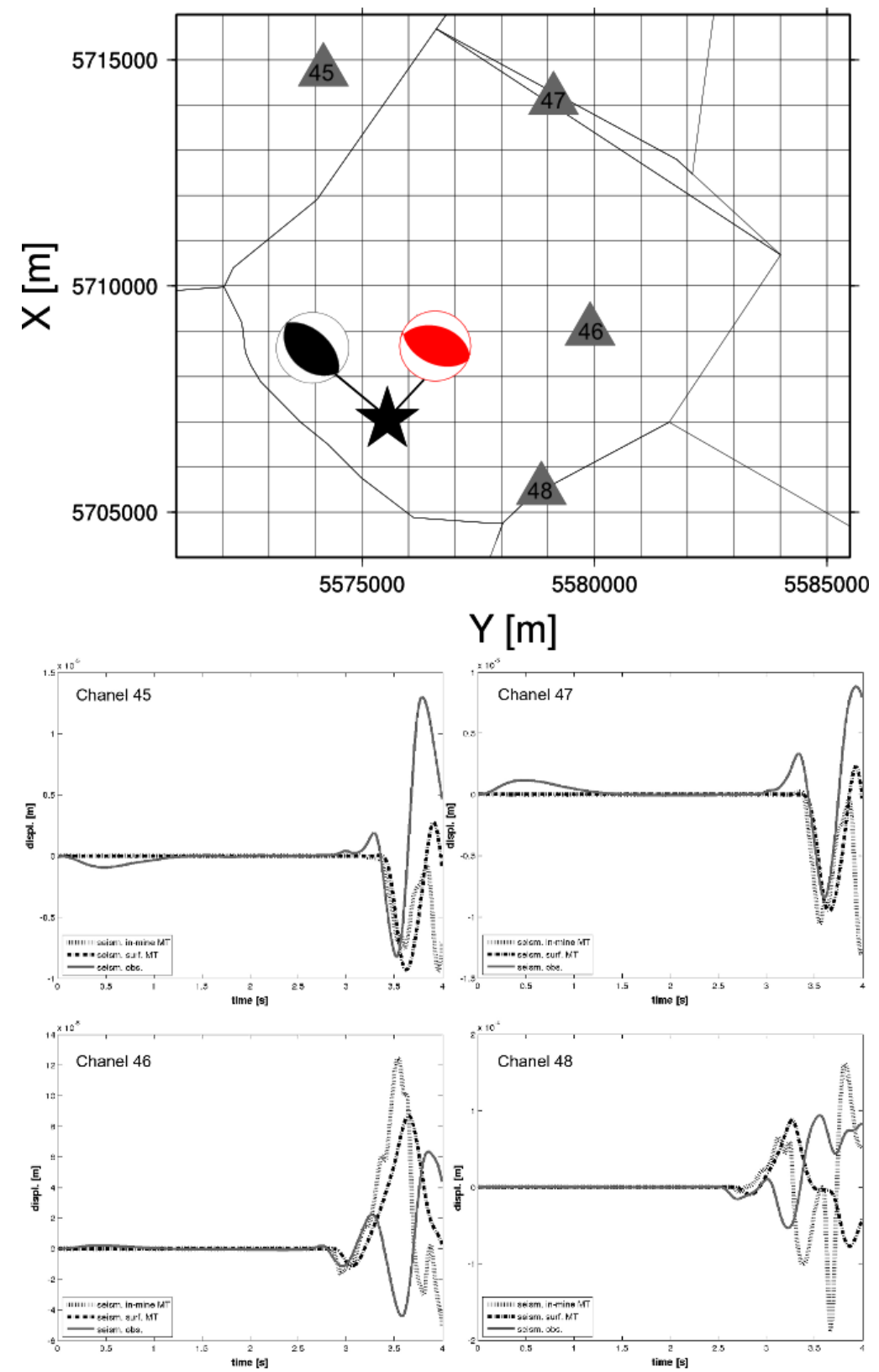

Fig. 7. Forward modeling results for full moment tensor solutions. The observed displacement signal filtered in frequency range $2-3 \mathrm{~Hz}$ for 4 in-mine stations is represented by solid line, the solution A and B synthetic displacement waveforms modeled in the same frequency range $(2-3 \mathrm{~Hz})$ are represented with thin dashed and thick dot-dashed lines, respectively. 
Table 3

Results of cross-correlation coefficients of the modelled waveforms and observed ones from the in-mine network

\begin{tabular}{|c|c|c|c|}
\hline $\begin{array}{c}\text { Chanel of Rudna } \\
\text { Mine network }\end{array}$ & $\begin{array}{c}\text { Solution A - } \\
\text { Observed waveform } \\
\text { correlation }\end{array}$ & $\begin{array}{c}\text { Solution B - } \\
\text { Observed waveform } \\
\text { correlation }\end{array}$ & $\begin{array}{c}\text { Solution A - } \\
\text { Solution B } \\
\text { correlation }\end{array}$ \\
\hline Channel 45 & 0.72 & 0.73 & 0.98 \\
Channel 46 & 0.66 & 0.61 & 0.92 \\
Channel 47 & 0.49 & 0.64 & 0.95 \\
Channel 48 & 0.45 & 0.53 & 0.42 \\
\hline Average & 0.58 & 0.63 & 0.81 \\
\hline
\end{tabular}

The values of the correlation coefficients for the modelled waveforms are presented in Table 3. Visual comparison shows that the solution A more accurately resolves the first onset of the $P$ waves in terms of the polarity and amplitude, while the solution $\mathrm{B}$ is more accurate in resolving the longer $P$-wave train, especially in terms of the amplitude values. Neither of the synthetic displacement waveforms fits the whole observed $P$-wave displacement waveform perfectly well. The correlation of observed signal and synthetic ones are, in average, around 0.6 for both tensors used as source models. In case of two channels of solution A correlation coefficient value is lower than 0.5 while for solution B in every examined channel this values are higher than 0.5 . Channel 48 waveform was the worst modeled one by both solutions even in terms of cross-correlation of both synthetic waveforms it has the lowest coefficient value, below 0.5 . The azimuth between the event epicentre and the station was almost parallel to the strike of the nodal planes, and that is why the poor signal correlation may be expected due to the radiation pattern of the waves. Only in case of channel 46, the solution A modelling obtained higher cross-correlation coefficient than the solution B. According to the forward modelling approach, the solution B is better in terms of retrieving waveform within range of 2-3 Hz. But both solutions of Moment Tensor allowed to model very similar waveforms - their cross-correlation coefficient of synthetic waveforms is, in average, about 0.8 (Table 3 ), but in case of 3 out of 4 modelled records it is above 0.9 , in agreement with the nodal plane orientations of both solutions, which do not differ much (up to 24 degrees). The main difference in results obtained in forward modelling of waveforms with the use of Moment Tensors comes from the different frequency range covered by the data used in Moment Tensor inversion.

Solution A Moment Tensor was obtained with the use of first $P$-wave pulse (frequency range $4-16 \mathrm{~Hz}$ ), while the solution $\mathrm{B}$ was obtained with 
waveform inversion in $2-3 \mathrm{~Hz}$ band. In case of surface recordings used for solution B inversion, the high frequency part of the signal is not recorded because of the scattering and attenuation through the ray path and the thick sediment layers working as a natural filter.

The aftershock sequences in LGCD are rare; they were observed only in case of the two biggest events (Gibowicz et al. 1979, 1989). In those cases, the location of the aftershock and their mechanisms were reported as consistent with the main event focal mechanism fault plane orientation. Aftershocks of 19 March event are mainly concentrated within the G-3/4 mining panel where the main event occurred. All of them were located on SW wing of the Rudna Główna Fault (Fig. 3). The aftershocks location was in ceiling above the ore bearing strata (Koziarz 2013), but it does not align with the Rudna Główna Fault, while the main event nodal plane strikes are almost parallel to the Rudna Główna Fault strike reported as 285 to 295 degrees. This fault is dipping towards NE (Koziarz 2013), while the resulting solutions had a dip between 43 and 45 degrees, consistent with the fault dip. Moreover, there are only 2 groups of crack orientations observed in rockmass within the G-3/4 mining panel, which are of about 290 and about 25 degrees (Koziarz 2013).

For 7 biggest aftershocks $\left(E \approx 10^{4} \mathrm{~J}\right)$ it was possible to calculate focal mechanism with the use of $P$-wave amplitude inversion. The obtained focal mechanisms were mostly non-DC with CLVD component range from 59 to $87 \%$ with reverse fault regime. The aftershocks (Table 4) can be divided into three groups: first with nodal plane orientations almost parallel to the main

Table 4

Aftershock nodal plane orientation and full moment tensor components

\begin{tabular}{|c|c|c|c|c|}
\hline \multicolumn{2}{|c|}{ Aftershock } & $\begin{array}{c}\text { Nodal plane 1 } \\
\text { Strike/dip/slip }\end{array}$ & $\begin{array}{c}\text { Nodal plane 2 } \\
\text { Strike/dip/slip }\end{array}$ & $\begin{array}{c}\text { Full moment tensor } \\
\text { components } \\
\text { ISO/CLVD/DC } \\
\text { [\%] }\end{array}$ \\
\hline No. & Time & & & $21 / 67 / 12$ \\
1 & 19 Mar 2013, 22:13:17 & $155 / 53 / 86$ & $342 / 38 / 96$ & $23 / 71 / 6$ \\
2 & 19 Mar 2013, 22:59:25 & $122 / 52 / 92$ & $298 / 37 / 87$ & $21 / 64 / 15$ \\
3 & 19 Mar 2013, 23:05:28 & $108 / 59 / 94$ & $280 / 31 / 83$ & $11 / 87 / 2$ \\
4 & 19 Mar 2013, 23:27:39 & $130 / 50 / 89$ & $311 / 41 / 91$ & $21 / 59 / 20$ \\
5 & 19 Mar 2013, 23:45:18 & $134 / 54 / 93$ & $309 / 37 / 86$ & $13 / 75 / 12$ \\
6 & 20 Mar 2013, 00:14:47 & $46 / 48 / 98$ & $214 / 43 / 82$ & $14 / 77 / 9$ \\
7 & 20 Mar 2013, 08:41:08 & $44 / 47 / 97$ & $214 / 44 / 83$ & \\
\hline
\end{tabular}


crack orientations (aftershocks Nos. 6 and 7), second with nodal plane similar to the obtained orientation of the main event (aftershocks Nos. 2-5), and third not aligned to any of reported discontinuities (aftershock No. 1).

The results of aftershock analysis are in good agreement with main event mechanism. The nodal plane orientations of aftershocks, as well as their locations, indicate the reverse faulting regime of the main event and following roof collapse, which activated the ceiling weakened zones on SW wing of Rudna Główna Fault. It is consistent with Rudna Główna Fault plane orientation dipping toward NE, while the main event reverse faulting caused a relative upward movement of NE wing toward SW.

\section{MACROSEISMIC DATA}

The macroseismic questionnaire with felt reports, intensity and consequences of the earthquake was placed on the web page of the Institute of Geophysics, Polish Academy of Sciences (IGF PAS). Local authorities were informed about the survey and were very helpful in distribution of the ques-

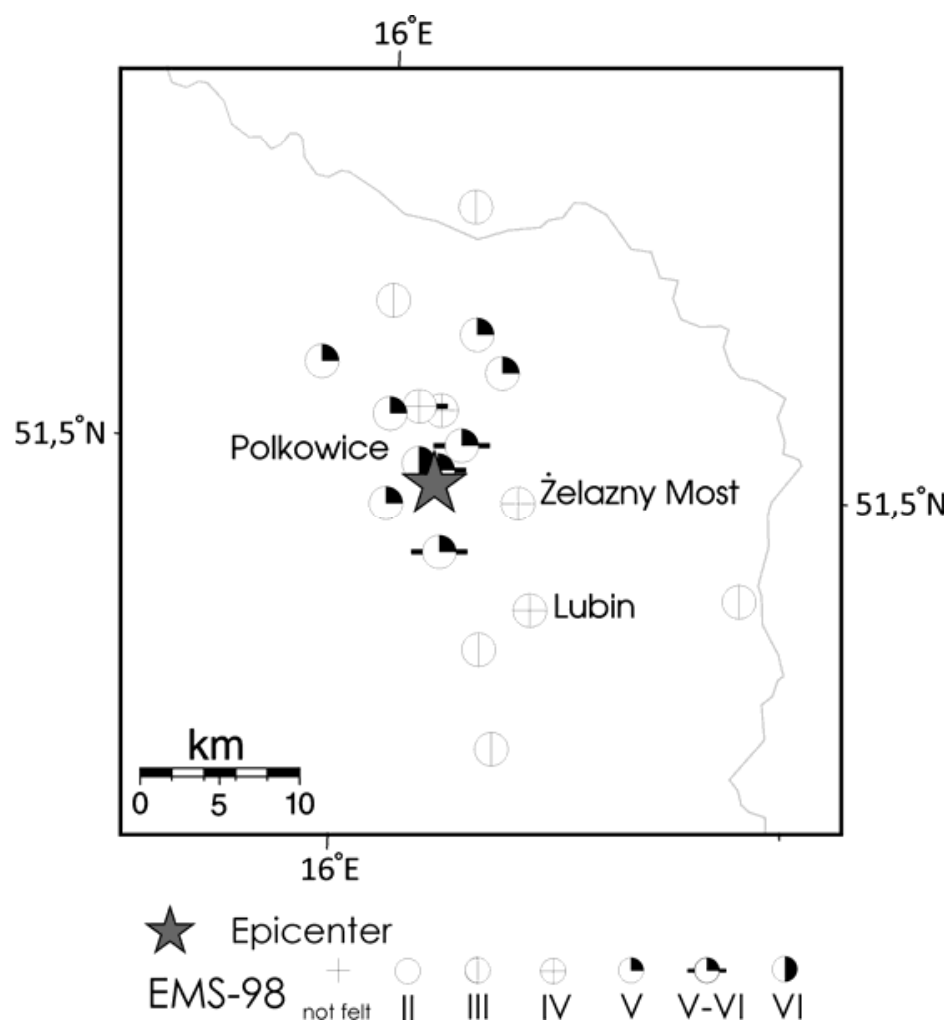

Fig. 8. Map of felt intensity of the tremor on 19 March 2013, from Polkowice and its vicinity. 
tionnaire in the local communities. As a result, about 100 questionnaires have been filled in, which is not representative for a full macroseismic analysis including isoseismal maps. Analysis of such a small number of inquiries gave only rough estimation of the scale of intensity of macroseismic effect. People reported oscillations, swinging of the lamps, movement of small objects and chairs, opening/closing of windows or doors, also minor cracks on walls and chimneys. The citizens of Polkowice reported that it was the most powerful tremor they experienced in the last couple of years. The earthquake was felt mainly in Polkowice town and its surroundings, in Głogów and Lubin towns. The felt reports cover an area up to $20 \mathrm{~km}$ from the epicenter (Fig. 8). The highest intensity was VI according to EMS-98 scale (Grünthal 1998) it was reported from a small area close to the epicenter, not farther than $2 \mathrm{~km}$; the next reports of V-VI intensity levels were reported from the area up to $8 \mathrm{~km}$ to the south from the epicenter. The macroseismic observations confirm that the event was shallow; the area of the highest intensity was small and limited to the closest vicinity of the source epicentre location. Unfortunately, the small number of filled questionnaires did not allow to perform any analysis of directivity of the intensity according to the focal mechanism solutions.

\section{DISCUSSION AND CONCLUSIONS}

The seismic event of 19 March 2013, was the third most powerful event recorded in LGCD, $M l=4.2$. The felt reports described this event as an exceptionally strong and broadly felt in comparison with other induced events from LGCD area in the last couple of years. It was a very dangerous event with rockburst and high degradation of the mining panel installations. Onsite examinations brought the following conclusions: there were floor cracks observed after the event, which were not continued in the roof and the rockburst was limited only to the very thin part of the roof (Koziarz 2013). The main rockmass of the roof in the panel was stable and solid. The event's location was within the fault zone at the depth of excavation, but the floor deformation and stable ceiling suggest that the rupture started below the excavation level. Taking into account that the depth determination is not as accurate as epicentral location (Rudziński and Dębski 2011) and the radius of the rupture was about $200 \mathrm{~m}$, those observations are consistent with instrumental data.

The mechanism of the event was complex, but the rupture initially acted as a reverse fault, although the Rudna Główna Fault is a normal one; therefore, a possible scenario of this event is that the mining works changed the stress state in the rockmass near the fault zone. The result was that the fault regime was reverse. When the accumulated energy overcame the friction the fault plane acting as the weakest part of the medium, the rupture and move- 
ment followed the old fault plane orientation. It is confirmed by the focal mechanism solutions, that the nodal plane strikes are almost parallel to the Rudna Główna Fault strike reported as 285 to 295 degrees. This fault is dipping towards NE (Koziarz 2013), while the resulting solutions had a dip between 43 and 45 degrees, which is consistent with the fault dip. Moreover, there are only 2 groups of crack orientations observed in rockmass within the G-3/4 mining panel: about 290 and about 25 degrees (Koziarz 2013).

The amplitude inversion results of Full Moment Tensor (solution A) differ from those obtained with the waveform inversion (solution B) most probably due to the uncertainty of the velocity model, poorer azimuthal coverage for the latter method and different frequency ranges of the observed signals used for inversion. Comparison of the results with forward modelling described in Section 3 shows that the in-mine network and LUMINEOS network records are dominated by different frequency ranges, which correspond to the different rupture stages. The high frequency $P$-wave observations of in-mine network used for inversion allowed to retrieve the initial rupture of the studied event, which had a complex character, but its orientation was parallel to the pre-existing cracks of the Rudna Glówna Fault zone. The rupture acted on the weak part of the fault zone. The initial rupture was then followed by the rockburst, which dominated the surface records with the lower frequency signal. This was much better retrieved from the waveform inversion (solution B) in terms of the forward modelling test results. The methods used for Moment Tensor solutions are complementary and allow to describe the rupture during the event. Both mechanism solution results support the hypothesis that this event was induced along a pre-existing fault. Some geomechanical works, such as Marcak and Mutke (2013), support the thesis that mining stress changes play a significant role in the reverse faulting mechanism occurrence. This work was focused on an influence of stress changes caused by mining on tectonic stress in Polish coal mines. Similar works in LGCD may in future put some new light onto the mechanism of the stress pattern change. Currently, there is no proof in the available data for reactivation of the tectonic processes in this area, which is considered as inactive.

Acknowledgments. We express our gratitude to Mr. Eugeniusz Koziarz, Head of the Rudna Mine Seismological Station, for help and provision of data necessary for our analysis.

This paper is partially supported by Institute of Geophysics scientific project No. 3d/IGFPAN/2013mł. 


\section{References}

Aki, K., and P.G. Richards (1980), Quantative Seismology: Theory and Methods, W.H. Freeman \& Co., San Francisco.

Awad, H., and G. Kwiatek (2005), Focal mechanism of earthquakes from the June 1987 swarm in Aswan, Egypt, calculated by the moment tensor inversion, Acta Geophys. Pol. 53, 3, 275-291.

Boatwright, J., and J.B. Fletcher (1984), The partition of radiated energy between P and S waves, Bull. Seismol. Soc. Am. 74, 2, 361-376.

Boore, D.M., and J. Boatwhright (1984), Average body-wave radiation coefficients, Bull. Seismol. Soc. Am. 74, 5, 1615-1621.

Brune, J.N. (1970), Tectonic stress and the spectra of seismic shear waves from earthquakes, J. Geophys. Res. 75, 26, 4997-5009, DOI: 10.1029/ JB075i026p04997.

Brune, J.N. (1971), Correction to "Tectonic stress and the spectra, of seismic shear waves from earthquakes", J. Geophys. Res. 76, 20, 5002, DOI: 10.1029/JB076i020p05002.

Cesca, S., E. Buforn, and T. Dahm (2006), Amplitude spectra moment tensor inversion of shallow earthquakes in Spain, Geophys. J. Int. 166, 2, 839-854, DOI: 10.1111/j.1365-246X.2006.03073.x.

Cesca, S., S. Heimann, K. Stammler, and T. Dahm (2010), Automated procedure for point and kinematic source inversion at regional distances, J. Geophys. Res. 115, B6, B06304, DOI: 10.1029/2009JB006450.

Cesca, S., A. Rohr, and T. Dahm (2013), Discrimination of induced seismicity by full moment tensor inversion and decomposition, J. Seismol. 17, 1, 147163, DOI: 10.1007/s10950-012-9305-8.

Davi, R., and V. Vavryčuk (2012), Seismic network calibration for retrieving accurate moment tensors, Bull. Seismol. Soc. Am. 102, 6, 2491-2506, DOI: $10.1785 / 0120110344$.

Dec, J., K. Pietsch, and P. Marzec (2011), Application of seismic methods to identify potential gas concentration zones at the Zechstein Limestone level in the "Rudna" mining area, SW Poland, Ann. Soc. Geol. Pol. 81, 1, 63-78.

EMSC (2013), M 4.6 - Poland - 2013-03-19 21:09:52 UTC, Lastquake - the official EMSC earthquakes app, http:/www.emsc-csem.org/Earthquake/ earthquake.php?id=308921.

Fitch, T.J., D.W. McCowan, and M.W. Shields (1980), Estimation of seismic moment tensor from teleseismic body wave data with applications to intraplate and mantle earthquakes, J. Geophys. Res. 85, B7, 3817-3828, DOI: 10.1029/JB085iB07p03817.

Gibowicz, S.J., and A. Kijko (1994), An Introduction to Mining Seismology, Academic Press, San Diego. 
Gibowicz, S.J., A. Bober, A. Cichowicz, Z. Droste, Z. Dychtowicz, J. Hordejuk, M. Kazimierczyk, and A. Kijko (1979), Source study of the Lubin, Poland, tremor of 24 March 1977, Acta Geophys. Pol. 27, 1, 3-38.

Gibowicz, S.J., J. Niewiadomski, P. Wiejacz, and B. Domański (1989), Source study of the Lubin, Poland, mine tremor of 20 June 1987, Acta Geophys. Pol. 37, 2, 111-132.

Grünthal, G. (1998), EMS-98: European Macroseismic Scale 1998, Cahiers du Centre Européen de Géodynamique et de Séismologie, Vol. 15, Centre Européen de Géodynamique et de Séismologie, Luxembourg.

Guterch, B., and H. Lewandowska-Marciniak (2002), Seismicity and seismic hazard in Poland, Fol. Quater. 73, 85-99.

Guterch, B., H. Lewandowska-Marciniak, and J. Niewiadomski (2005), Earthquakes recorded in Poland along the Pieniny Klippen Belt, Western Carpathians, Acta Geophys. Pol. 53, 1, 27-45.

Hanks, T.C., and H. Kanamori (1979), A moment magnitude scale, J. Geophys. Res. 84, B5, 2348-2350, DOI: 10.1029/JB084iB05p02348.

Haskell, N.A. (1953), The dispersion of surface waves on multilayered media, Bull. Seismol. Soc. Am. 43, 1, 17-34.

Heimann, S. (2011), A robust method to estimate kinematic earthquake source parameters, Ph.D. Thesis, University of Hamburg, Hamburg, Germany.

KGHM (2013), KGHM Polska Miedź S.A., Rudna mine, http://www.kghm.pl/ index.dhtml?category_id=265_24.06.2013\&laang=en.

Koziarz, E. (2013), Personal communication.

Kwiatek, G. (2013), http://www.induced.pl/projekty/foci (in Polish).

Lasocki, S. (2005), Probabilistic analysis of seismic hazard posed by mining induced events. In: Y. Potvin, and M. Hudyma (eds.), Proc. Sixth Int. Symp. on Rockburst and Seismicity in Mines "Controlling Seismic Risk", 9-11 March 2005, Australian Centre for Geomechanics, Nedlands, Australia, 151-156.

Leśniak, A., and G. Pszczoła (2008), Combined mine tremors source location and error evaluation in the Lubin Copper Mine (Poland), Tectonophysics 456, 1-2, 16-27, DOI: 10.1016/j.tecto.2007.04.012.

Lizurek, G., and P. Wiejacz (2011), Moment tensor solution and physical parameters of selected recent seismic events at Rudna Copper Mine. In: A.F. Idziak and R. Dubiel (eds.), Geophysics in Mining and Environmental Protection, Geoplanet: Earth and Planetary Sciences, Springer, Berlin Heidelberg, 1119, DOI: 10.1007/978-3-642-19097-1_2.

Lizurek, G., B. Plesiewicz, P. Wiejacz, J. Wiszniowski, and J. Trojanowski (2013), Seismic event near Jarocin (Poland), Acta Geophys. 61, 1, 26-36, DOI: 10.2478/s11600-012-0052-6.

Madariaga, R. (1976), Dynamics of expanding circular fault, Bull. Seismol. Soc. Am. 66, 3, 639-666. 
Marcak, H., and G. Mutke (2013), Seismic activation of tectonic stresses by mining, J. Seismol. 17, 4, 1139-1148, DOI: 10.1007/s10950-013-9382-3.

Medhurst, T., M. Bartlett, and R. Sliwa (2008), Effect of Grouting on Longwall Mining Through Faults. In: N. Aziz (ed.), Coal 2008: Coal Operators' Conference, 14-15 February 2008, University of Wollongong and the Australasian Institute of Mining and Metallurgy, Australia, 44-55.

Niewiadomski, J. (1997), Spectral analysis and seismic source parameters. In: A.J. Mendecki (ed.), Seismic Monitoring in Mines, Chapman \& Hall, London, 144-158.

Rudziński, Ł., and W. Dębski (2011), Extending the double-difference location technique to mining applications. Part I: Numerical study, Acta Geophys. 59, 4, 785-814, DOI: 10.2478/s11600-011-0021-5.

Tajduś, A., T. Majcherczyk, and M. Cała (1996), Effect of faults on rockbursts hazard. In: Z. Rakowski (ed.), Geomechanics'96, Balkema, Rotterdam.

Vavryčuk, V. (2005), Focal mechanisms in anisotropic media, Geophys. J. Int. 161, 2, 334-346, DOI: 10.1111/j.1365-246X.2005.02585.x.

Wiejacz, P. (1992), Calculation of seismic moment tensor for mine tremors from the Legnica-Głogów Copper Basin, Acta Geophys. Pol. 40, 2, 103-122.

Wiejacz, P., and W. Dębski (2009), Podhale, Poland, earthquake of November 30, 2004, Acta Geophys. 57, 2, 346-366, DOI: 10.2478/s11600-009-0007-8.

Zuchiewicz, W., J. Badura, and M. Jarosiński (2007), Neotectonics of Poland: An overview of active faulting, Stud. Quater. 24, 5-20.

Received 25 July 2013

Received in revised form 17 July 2014

Accepted 22 July2014 